\title{
In Vivo Synaptic Scaling Is Mediated by GluA2-Lacking AMPA Receptors in the Embryonic Spinal Cord
}

\author{
Miguel Angel Garcia-Bereguiain, Carlos Gonzalez-Islas, Casie Lindsly, Ellie Butler, Atlantis Wilkins Hill, \\ and Peter Wenner \\ Department of Physiology, Emory University School of Medicine, Atlanta, Georgia 30322
}

When spiking activity within a network is perturbed for hours to days, compensatory changes in synaptic strength are triggered that are thought to be important for the homeostatic maintenance of network or cellular spiking activity. In one form of this homeostatic plasticity, called synaptic scaling, all of a cell's AMPAergic miniature postsynaptic currents (mEPSCs) are increased or decreased by some scaling factor. Although synaptic scaling has been observed in a variety of systems, the mechanisms that underlie AMPAergic scaling have been controversial. Certain studies find that synaptic scaling is mediated by GluA2-lacking calcium receptors (CP-AMPARs), whereas others have found that scaling is mediated by GluA2-containing calcium-impermeable receptors (CI-AMPARs). Spontaneous network activity is observed in most developing circuits, and in the spinal cord this activity drives embryonic movements. Blocking spontaneous network activity in the chick embryo by infusing lidocaine in vivo triggers synaptic scaling in spinal motoneurons; here we show that AMPAergic scaling occurs through increases in mEPSC conductance that appear to be mediated by the insertion of GluA2-lacking AMPA receptors at the expense of GluA2-containing receptors. We have previously reported that in vivo blockade of $\mathrm{GABA}_{\mathrm{A}}$ transmission, at a developmental stage when GABA is excitatory, also triggered AMPAergic synaptic scaling. Here, we show that this form of AMPAergic scaling is also mediated by CP-AMPARs. These findings suggest that AMPAergic scaling triggered by blocking spiking activity or $\mathrm{GABA}_{\mathrm{A}}$ receptor transmission represents similar phenomena, supporting the idea that activity blockade triggers scaling by reducing $\mathrm{GABA}_{\mathrm{A}}$ transmission.

\section{Introduction}

Homeostatic synaptic plasticity is the process of homeostatically maintaining activity levels through compensatory adjustments in synaptic strength (Rich and Wenner, 2007; Vitureira et al., 2012; Turrigiano, 2012). For example, when network activity was blocked in cultured neural networks for days, increases in the amplitude of excitatory miniature postsynaptic currents (mPSCs) and decreases in the amplitude of inhibitory mPSCs were observed (O’Brien et al., 1998; Turrigiano et al., 1998). These compensatory changes in mPSC amplitude occur through a multiplicative process where the entire distribution of amplitudes appears to be scaled by a multiplicative factor (synaptic scaling) (Turrigiano et al., 1998). The mechanisms that underlie compensatory changes in excitatory and inhibitory quantal amplitude after activity blockade of cultured networks include changes in postsynaptic receptor number, subunit composition, and the amount of transmitter released per vesicle (Rich and

\footnotetext{
Received Aug. 20, 2012; revised Feb. 26, 2013; accepted March 8, 2013.

Author contributions: M.A.G.-B., C.G.-I., C.L., and P.W. designed research;M.A.G.-B., C.G.-I., C.L., E.B., and A.W.H. performed research; M.A.G.-B., C.G.-I., C.L., and P.W. analyzed data; M.A.G.-B., C.G.-I., C.L., and P.W. wrote the paper.

This work was supported by the National Institute of Neurological Disorders and Stroke, the Whitehall Foundation, and the Neilsen Foundation (P.W.). M.A.G.-B. was supported by a fellowship from Rafael del Pino Foundation. We thank Dr. Steve Traynelis for his valuable comments on the manuscript.

The authors declare no competing financial interests.

Correspondence should be addressed to Dr. Peter Wenner, Emory University School of Medicine, Department of Physiology, Room 601, Whitehead Building, Atlanta, GA 30322. E-mail: pwenner@emory.edu.

DOI:10.1523/JNEUROSCI.4025-12.2013

Copyright $\odot 2013$ the authors $\quad 0270-6474 / 13 / 336791-09 \$ 15.00 / 0$
}

Wenner, 2007; Turrigiano, 2008). However, much less is known about the mechanisms underlying synaptic scaling following activity perturbations in vivo.

Synaptic scaling of AMPAergic mPSCs has been shown to be mediated by changes in postsynaptic AMPA receptors in several studies (Lee, 2012). However, identifying which receptor subunits are involved has been a topic intense interest and debate as demonstrated by four separate reviews in the last two years that discuss the issue (Man, 2011; Lee, 2012; Shepherd, 2012; Turrigiano, 2012). Several studies in which network activity was blocked in cultured neurons suggest AMPAergic scaling was mediated by GluA2-containing CI-AMPARs alone, whereas several other studies demonstrate the involvement of GluA2-lacking CPAMPARs. Less is known about the mechanisms that mediate AMPAergic scaling after in vivo activity perturbations; however, evidence for and against the involvement of CP-AMPARs has been described in the developing visual system (Goel et al., 2006; Gainey et al., 2009; Goel et al., 2011).

We have shown an in vivo form of AMPAergic synaptic scaling in the chick embryo spinal cord, where compensatory changes in synaptic strength appear to contribute to the maintenance of spontaneous network activity (SNA) (Gonzalez-Islas and Wenner, 2006). SNA is the product of a highly excitable developing circuit where GABA is depolarizing and excitatory. SNA is observed in virtually all developing circuits and is thought to be important for the maturation of the synaptic networks in which it is expressed (O'Donovan et al., 1998; O'Donovan, 1999; Blankenship and Feller, 2010). In the spinal cord, SNA occurs as 
episodic bursts of activity, which drive embryonic movements (O'Donovan, 1999). Previously, we blocked SNA in the chick embryo by injection of a sodium channel blocker or $\mathrm{GABA}_{\mathrm{A}}$ antagonist in ovo for $2 \mathrm{~d}$ and observed a compensatory increase of glutamatergic mEPSC amplitude in motoneurons (GonzalezIslas and Wenner, 2006; Wilhelm and Wenner, 2008). It is unknown whether CP-AMPARs are involved in the in vivo AMPAergic scaling described in the embryonic spinal cord, and here we examine the possibility that CP-AMPARs mediate synaptic scaling at an early developmental stage when GABA is excitatory.

\section{Materials and Methods}

Dissection. Stage 36 (Hamburger and Hamilton, 1951) chick embryo spinal cords (of either sex), with intact spinal nerves, were dissected under cooled $\left(15^{\circ} \mathrm{C}\right)$ Tyrode's solution containing the following (in $\mathrm{mM}$ ): $139 \mathrm{NaCl}, 12$ glucose, $17 \mathrm{NaHCO} 3,3 \mathrm{KCl}, 1 \mathrm{MgCl}_{2}$, and $3 \mathrm{CaCl}_{2}$ ) (for a full description, see Gonzalez-Islas and Wenner, 2006). After the dissection, the cord was allowed to recover for at least $6 \mathrm{~h}$ in Tyrode's solution at $18^{\circ} \mathrm{C}$. The cord was then transferred to a recording chamber and continuously perfused with Tyrode's solution that was heated to $28^{\circ} \mathrm{C}$.

Electrophysiology. Whole-cell patch-clamp recordings were made from spinal motoneurons localized in lumbosacral segments $1-3$ to assess mPSCs, as described previously (Gonzalez-Islas et al., 2010). Briefly, whole-cell recordings (electrodes, 5-10 M $\Omega$ ) were obtained from antidromically identified motoneurons. Recordings were terminated whenever significant increases in input resistance $(\geq 20 \%)$ occurred. Extracellular solution for mPSC recordings for CP465022 or N-naphthyl acetylspermine (NASPM) experiments was Tyrode's solution with an additional $2 \mathrm{~mm} \mathrm{KCl}$ (total $5 \mathrm{~mm}$ ), TTX $(1 \mu \mathrm{M}), \mathrm{GABA}_{\mathrm{A}}$ receptor antagonist gabazine $(5 \mu \mathrm{M})$, and NMDA receptor antagonist APV $(50 \mu \mathrm{M})$. The intracellular patch solution for these experiments contained the following (in mM): $5 \mathrm{NaCl}, 100 \mathrm{~K}$-gluconate, $30 \mathrm{KCl}, 5 \mathrm{CsCl}, 10 \mathrm{TEA}-\mathrm{Cl}, 10$ HEPES, $1 \mathrm{MgCl}_{2}, 0.1 \mathrm{CaCl}_{2}, 1 \mathrm{Na}_{2} \mathrm{ATP}, 0.1 \mathrm{MgGTP}$. For $I-V$ plots and rectification measurements, the solutions were as follows: intracellular solution same as above with the following additions (in mM) 10 BAPTA, 10 QX-314, and 0.1 verapamil; extracellular solution same as above with the following additions (in mM) 30 TEA, $5 \mathrm{CsCl}$. Pipette solution osmolarity was between 280 and $300 \mathrm{mOsm}$, and $\mathrm{pH}$ was adjusted to 7.3 with $\mathrm{KOH}$. Junction potentials were corrected online. Currents were filtered online at $5 \mathrm{kHz}$, digitized at $10 \mathrm{kHz}$.

$I-V$ plots for mEPSCs were performed using an Axoclamp 2B, whereas all other whole-cell recordings were performed in a separate rig using an Axoclamp 200, which displayed better noise characteristics (see root mean square [RMS] values in figure legends). RMS values were acquired for each cell, measured from 3 separate trace epochs devoid of mEPSCs.

mEPSC analysis. The mEPSCs were analyzed using Minianalysis software (Synaptosoft). Bar charts and associated average values were obtained by determining the average mEPSC amplitude for each cell (variable number of mEPSCs/cell, $5 \mathrm{pA}$ cutoff), and then taking the average of all cells. Cumulative probability distribution shown in Figure $1 B$ were obtained by combining all the mEPSC amplitudes across cells in control or lidocaine-treated motoneurons. In addition, ranked mEPSC amplitude plots were constructed. Ranked plots were obtained by taking the same number of mEPSC amplitudes $(>30)$ from the same number of cells in different conditions (control or treated motoneurons, before and after adding NASPM). We then ranked them in an ascending manner and plotted them against each other for comparison (e.g., ranked values for control vs lidocaine-treated motoneurons; Fig. $1 C$ ). A strong linear fit $(r \geq 0.98)$ suggested that all mEPSC amplitudes from one distribution were multiplicatively related or scaled to the other distribution. If the slope, $\mathrm{m}$, was $>1$, then the amplitude distribution on the $y$-axis compared with the $x$-axis had increased by the multiplicative factor $\mathrm{m}$.

In ovo drug injections. At embryonic day 8 (E8), lidocaine hydrochloride aqueous solution ( $35 \mathrm{mg} / \mathrm{ml}$ plus $10 \mathrm{~mm}$ HEPES, $\mathrm{pH}$ 7.2) was continuously applied onto the chorioallantoic membrane of the embryos at a rate of $13.5 \mu \mathrm{l} / \mathrm{h}$, as described previously (Gonzalez-Islas and Wenner, 2006); control embryos did not receive saline injections, as no difference

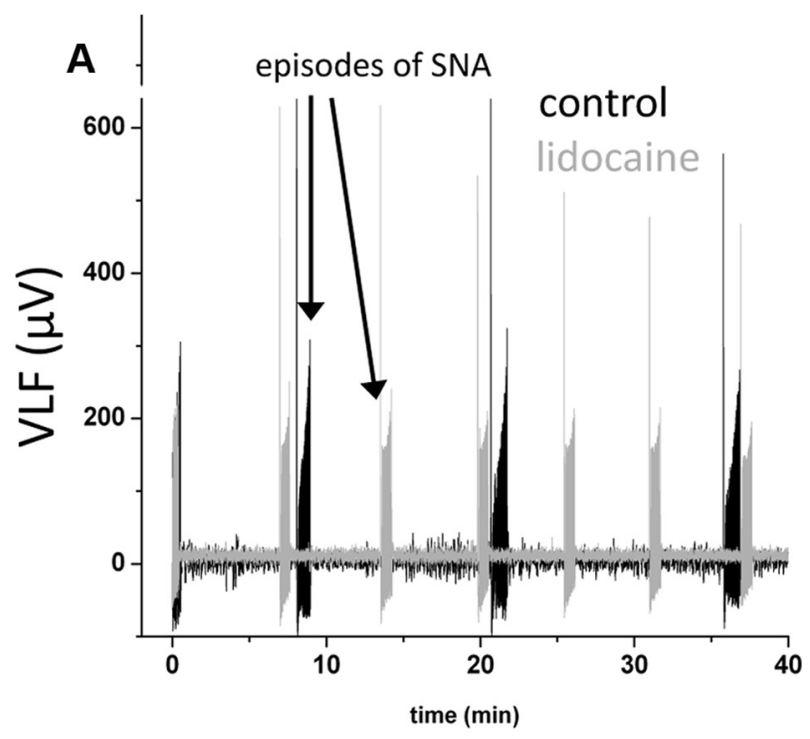

B
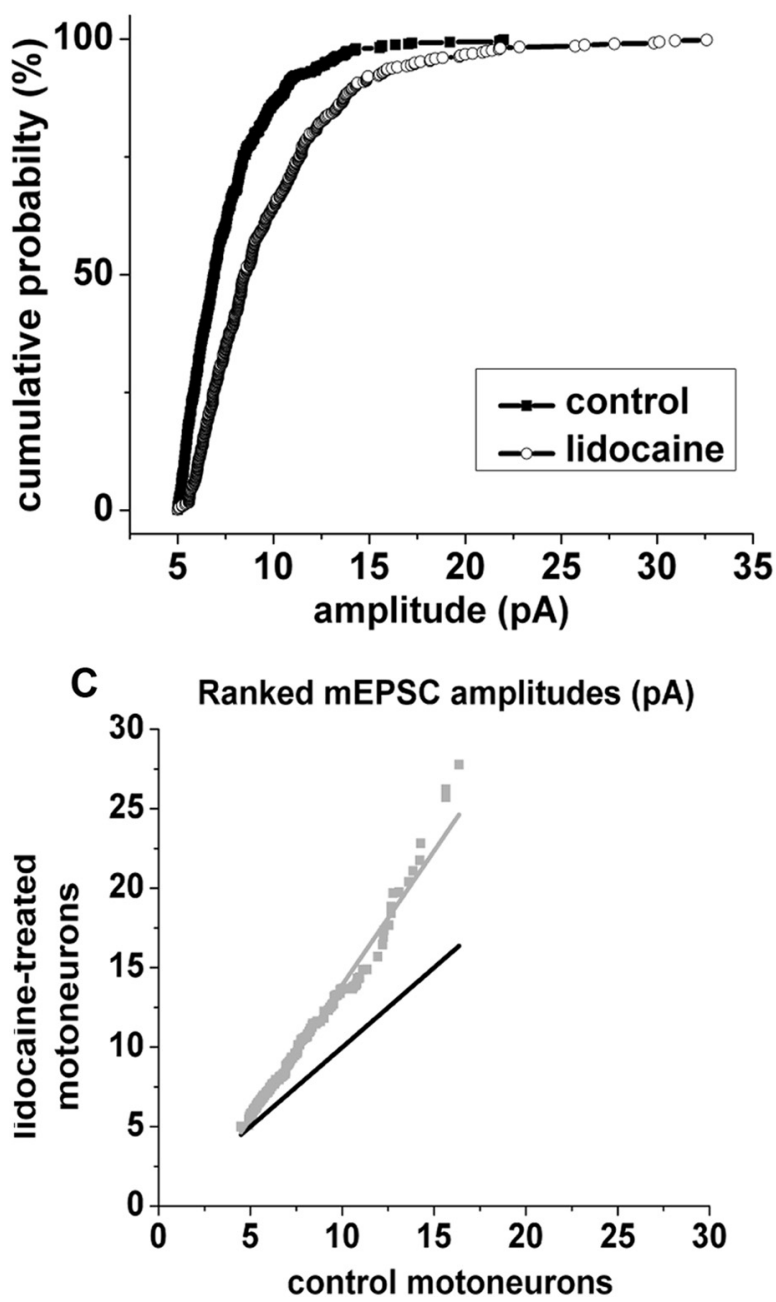

Figure 1. Lidocaine-treated embryos exhibit higher frequency of SNA and upward scaling of mEP$S C$ c compared with controls. $A$, Representative spinal nerve recordings showing the interval between episodes of SNA in isolated spinal cords from control (black) and lidocaine-treated embryos (gray). $\boldsymbol{B}$, Cumulative probability plot for glutamatergic mEPSC amplitudes from control and lidocaine-treated motoneurons ( 5 different cords, $n>400$ in both cases). C, Ranked mEPSC amplitudes from activityblocked motoneurons ( $y$-axis) plotted against corresponding ranked values of control motoneurons $(x$-axis). Black line represents expected result if amplitude distributions were the same. 
was observed between untreated and saline-treated embryos in this previous study. For gabazine treatments, a single bolus of gabazine was added at E8 to reach a concentration of $10 \mu \mathrm{M}$ in ovo, assuming a $50 \mathrm{ml}$ volume (Wilhelm and Wenner, 2008).

Drugs. Verapamil was purchased from Calbiochem; TTX, APV, CNQX, and CP465022 were purchased from Tocris Bioscience Cookson; $\mathrm{CsCl}$ was purchased from Fisher Scientific; BAPTA was purchased from Fluka; HEPES was purchased from Acros Organics. All other chemicals and drugs were purchased from Sigma-Aldrich.

Immunoblot. Ventral half lumbosacral spinal cords were homogenized in RIPA buffer supplemented with protease and phosphatase inhibitors (Sigma-Aldrich). Samples were then centrifuged at $16,000 \times g$ for $5 \mathrm{~min}$ to remove cell debris. Protein concentration was quantitated using BCA reagent (Pierce). Samples were separated on $4-15 \%$ SDS-PAGE and blotted to a nitrocellulose membrane. The primary antibodies to GluA1GluA4 subunits were from Abcam (rabbit anti-GluA1 ab31232, rabbit anti-GluA2 ab87610, rabbit anti-GluA3 ab87609, rabbit anti-GluA4 ab20673), and to actin (mouse anti-actin) from Sigma-Aldrich. The secondary antibodies used were HRP-goat anti-mouse IgG and HRP-goat anti-rabbit IgG from Sigma-Aldrich. The blot was visualized by ECL chemiluminescence (GE Healthcare). Quantitative analysis of protein expression was performed by drawing boxes around the protein bands and normalizing the signal intensity to actin intensity using Image ( National Institutes of Health). Blots were done in triplicate, and each sample represents a lysate of two or three different cords.

Statistics. Data are mean \pm SE. Most statistical analysis was performed using a two-tailed Student's $t$ test (paired and unpaired) unless mentioned otherwise. GraphPad Instat software and SigmaPlot 9 were used for statistical analysis.

\section{Results}

mEPSC membrane conductance increases in activity-blocked motoneurons

Previous studies in our laboratory have shown that $2 \mathrm{~d}$ blockade of embryonic movements in ovo led to increases in both SNA frequency and AMPA/kainate mEPSC amplitude in motoneurons from the isolated cord. To block SNA in ovo, lidocaine, a sodium channel blocker, was pumped continuously onto the chorioallantoic membrane of the chick from embryonic day 8 to 10 (E8-E10, stages 34-36). Spinal cords were isolated and maintained in recirculating Tyrode's solution in the absence of lidocaine. As shown in Figure 1A, the interval between the bouts or episodes of SNA was significantly reduced for lidocaine-treated embryos ( $4.4 \pm 0.8 \mathrm{~min}, n=6)$ compared with controls $(9.3 \pm$ $2.8 \mathrm{~min}, n=5)$. Whole-cell recordings were obtained from spinal motoneurons identified antidromically in either lidocainetreated or control embryos; mPSCs were recorded in voltageclamp at $-70 \mathrm{mV}$, and mEPSCs were pharmacologically isolated by bath application of gabazine $(5 \mu \mathrm{M})$ and APV $(50 \mu \mathrm{M})$. The average amplitude of mEPSCs from motoneurons of lidocainetreated embryos was 44\% larger than in control (control, $7.0 \pm$ $0.9 \mathrm{pA}, n=5$; lidocaine-treated, $10.1 \pm 2.8 \mathrm{pA}, n=5 ; p<0.01)$. These results were consistent with our previous study (GonzalezIslas and Wenner, 2006).

We also found that, after activity blockade, mEPSC amplitudes increased across the entire distribution (Fig. 1B). Indeed, mEPSC amplitudes underwent synaptic scaling as demonstrated in Figure $1 C$, which shows the plot of ranked mEPSC amplitude values for lidocaine-treated versus control motoneurons $(r=$ 0.99 and a slope value of $1.68 \pm 0.01, n=9$ cells; Fig. $1 C$ ). On the other hand, no significant change was found in the mEPSC frequency $(1.05 \pm 0.47 \mathrm{~Hz}$ and $1.16 \pm 0.40$ for control and lidocaine-treated embryos, respectively) or kinetics (5.8 $\pm 1.3 \mathrm{~ms}$ and $6.0 \pm 1.7 \mathrm{~ms}$ for control and lidocaine-treated embryos, respectively). In our previous study, we found that, after activity
A

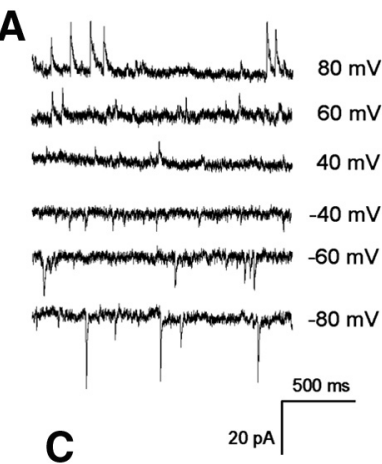

B
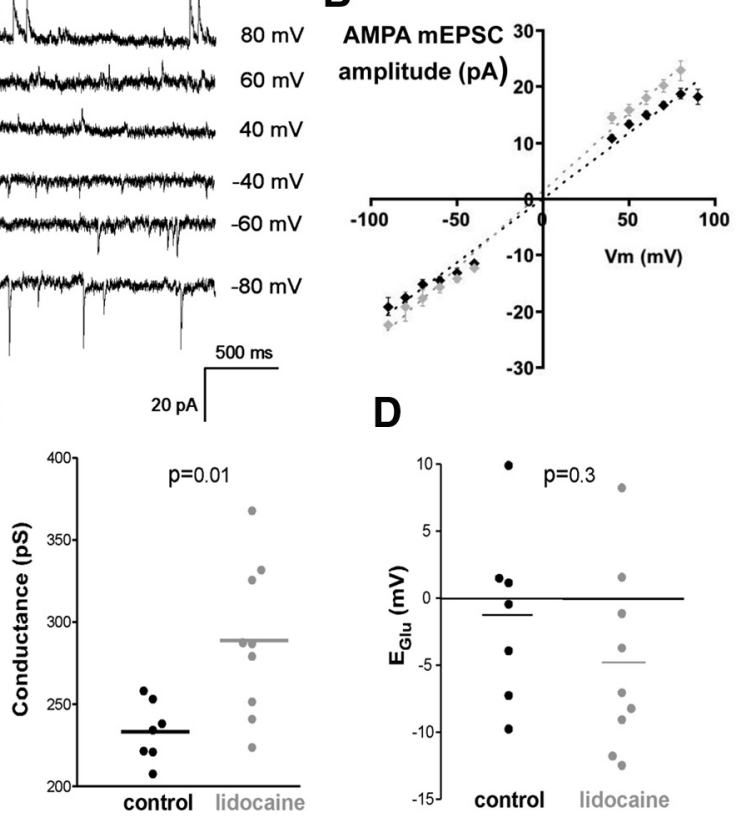

D

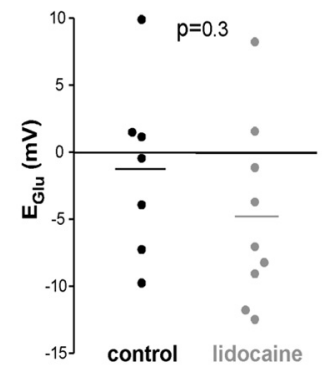

Figure 2. Conductance of mEPSCs was increased in activity-blocked motoneurons. $\boldsymbol{A}$ Voltage-clamp whole-cell recordings are shown in $20 \mathrm{mV}$ voltage steps in a motoneuron from an activity-blocked embryo. $\boldsymbol{B}$, The average amplitude of mPSCs at each step was plotted against the step voltage ( $I-V$ for control (black dots) and lidocaine-treated (gray dots) motoneurons. Error bars indicate SE. C, D, Scatter plots showing the average values obtained for $\mathrm{mEPSC}$ conductance $(\boldsymbol{C})$ and reversal potential $(\boldsymbol{D})$ for motoneurons from control (black dots, $n=7$ ) and lidocaine-treated embryos (gray dots, $n=9$ ). RMS values at $-70 \mathrm{mV}$ holding potential were $5.2 \pm 1.2$ for control and $4.7 \pm 1.1$ for lidocaine-treated motoneurons.

blockade, AMPAergic mEPSC amplitude did not multiplicatively scale and that mEPSC frequency was strongly increased (Gonzalez-Islas and Wenner, 2006). The discrepancy between our current and earlier study for these parameters is likely the result of our improved recordings, which allow better mEPSC detection (lower noise). In the previous study, it is likely that many small mEPSCs were not detected in control but were detected when amplitudes increased in activity-blocked motoneurons; this could explain the observed increase in mEPSC frequency and result in our inability to detect multiplicative scaling because we were not comparing the same populations of mEPSCs.

If mEPSC amplitude increases because of changes in postsynaptic AMPA receptors as others have shown, then we would expect changes in the conductance of the total population of channels that mediate an mEPSC (will refer to as mEPSC conductance). To assess mEPSC conductance, we constructed mEPSC $I-V$ plots using whole-cell recordings from control and activity-blocked motoneurons (as described previously for GABAergic mPSCs) (Gonzalez-Islas et al., 2009). Voltage-gated channels and NMDAergic and GABAergic transmission were blocked to isolate non-NMDA glutamatergic mEPSCs, which were typically recorded in voltage steps of $10 \mathrm{mV}$ for $1-2 \mathrm{~min}$ (Fig. $2 A$ ). The average peak amplitude of mEPSCs at each step was then plotted against voltage, for control and lidocaine-treated embryos (Fig. 2B). Spermine was not included in whole-cell patch solution to ensure that glutamate receptors did not rectify at positive potentials. A linear fit of the data from -90 to $90 \mathrm{mV}$ was then made, excluding data points from -30 to $30 \mathrm{mV}$ as these amplitudes tended to be overestimates as significant numbers of mEPSCs fell into the noise and were not detectable. mEPSC reversal potential was then determined 
as the X-intercept, and mEPSC conductance was taken as the slope of the fit. There was an increase in mEPSC conductance in lidocaine-treated embryos $(287.6 \pm 20.4$ pS) compared with controls $(235.8 \pm 16.3$ $\mathrm{pS}$ ), as shown in Figure 2C. However, no significant difference was observed in mEPSC reversal potential between motoneurons from control $(-2.4 \pm 7.2 \mathrm{mV})$ and lidocaine-treated embryos $(-2.7 \pm 7.1$ $\mathrm{mV}$; Fig. 2D). These results suggest that the increase in mEPSC amplitude observed in activity-blocked motoneurons was the result of an increase in mEPSC conductance.

Glutamatergic mEPSCs are mediated by AMPA (GluA1-GluA4) receptors in both control and activity-blocked motoneurons

As we have previously reported for E10 chick motoneurons, glutamatergic mEPSCs are virtually abolished with bath application of the AMPA/kainate receptor antagonist CNQX at $-70 \mathrm{mV}$ (Gonzalez-Islas and Wenner, 2006). To examine the contribution of AMPA versus kainate receptors mediating the mEPSCs, we bath applied the AMPA-selective antagonist (GluA1-GluA4), CP465022 (5 $\mu \mathrm{M}$; incubation time was at least $30 \mathrm{~min}$ ) (Lazzaro et al., 2002). Figure 3 shows that glutamatergic mEPSCs (isolated with the $\mathrm{GABA}_{\mathrm{A}}$ antagonist gabazine) are dramatically reduced in frequency when $\mathrm{CP} 465022$ is added to the bath in both control (from $0.72 \pm 0.12 \mathrm{~Hz}$ to $0.16 \pm 0.04$ $\mathrm{Hz}, p<0.001$ ) and lidocaine-treated motoneurons (from $0.89 \pm$ $0.30 \mathrm{~Hz}$ to $0.18 \pm 0.04 \mathrm{~Hz}, p<0.001$ ). Therefore, the vast majority of the recorded glutamatergic mEPSCs are mediated by AMPA receptors.

Activity blockade-induced scaling of AMPAergic mEPSCs through an increase of GluA2-lacking AMPA receptors To examine whether AMPAergic scaling after activity blockade is the result of changes in AMPA receptor subunit composition, we performed Western blots for GluA1-GluA4 subunits from lysates of the ventral half of the spinal cord from control and activityblocked embryos. As we show in Figure 4, lidocaine treatment induced a strong reduction in the total level of the GluA2 subunit $(44.7 \pm 2.7 \%$ of control value, $p<0.01)$. However, there were not significant changes in total protein level for any of the other AMPA receptor subunits. Therefore, the increase of AMPAergic mEPSC amplitude and conductance after lidocaine treatment is associated with a reduction of the expression of the GluA2 AMPA receptor subunit.

The reduction in GluA2 AMPA receptor protein suggested the possibility that activity blockade had increased the number of GluA2-lacking AMPA receptors, which have been shown to exhibit greater single-channel conductance than GluA2-containing receptors (Swanson et al., 1997). To functionally test this possibility, we took advantage of the fact that GluA2-lacking receptors display an inward rectification of the current at positive holding potentials (Donevan and Rogawski, 1995). We functionally measured the contribution of GluA2-lacking receptors by determining a rectification index, calculated as the average mEPSC amplitude at a $40 \mathrm{mV}$ holding potential divided by the average amplitude at a $-70 \mathrm{mV}$ holding potential. Spermine $(0.1 \mathrm{~mm})$ was added to the patch solution here to observe rectification. Consistent with our biochemical data, lidocaine-treated mo-

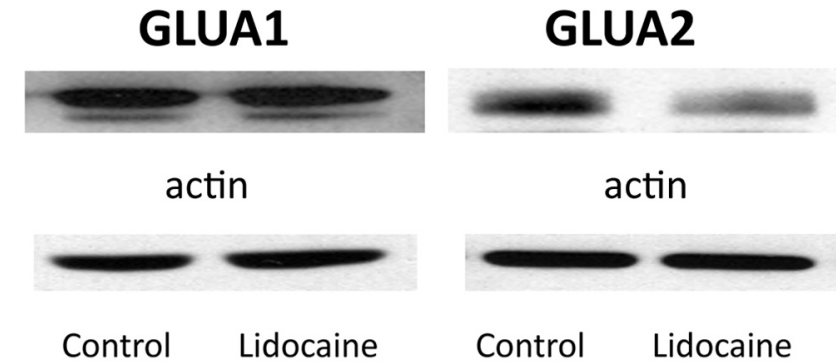

\section{GLUA3}

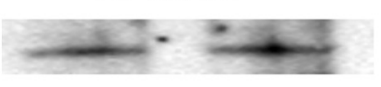

actin

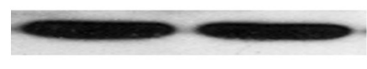

Control Lidocaine

Control

GLUA4

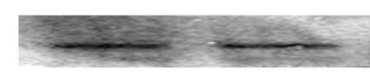

actin

Figure 4. GluA2 subunit in the ventral spinal cord is reduced in activity-blocked embryos. Western blots are shown for GluA1-GluA4 (upper bands) and actin (lower bands) of ventralhalf spinal cords of control and lidocaine-treated embryos. The average values of band intensity (normalized to actin) for the GluA2 subunit were significantly different $(p<0.01)$ between control and lidocaine-treated embryos (values are described in Results). No significant difference was observed in control and activity-blocked embryos for GluA1, GluA3, or GluA4 AMPA receptor subunits ( $n=4$ for each subunit in both control and activity-blocked embryos).

toneurons exhibited an inward rectification of AMPAergic mPSCs (reduction of the rectification index: $1.09 \pm 0.16$ for control and $0.59 \pm 0.11$ for activity-blocked motoneurons, $p<0.01$; Fig. 5 ). The reduction in rectification index from control to lidocainetreated motoneurons was the result of a decrease in mPSC amplitude at $40 \mathrm{mV}$ and an increase in amplitude at $-70 \mathrm{mV}(40$ $\mathrm{mV}$ : control, $12.5 \pm 5.4 \mathrm{pA}$; lidocaine, $7.8 \pm 3.3 \mathrm{pA} ;-70 \mathrm{mV}$ : control, $9.0 \pm 4.7 \mathrm{pA}$; lidocaine, $13.4 \pm 5.8 \mathrm{pA}$ ). These results demonstrate a postsynaptic insertion of CP-AMPARs after activity blockade.

To confirm these findings in lidocaine-treated motoneurons, we used a selective antagonist for GluA2-lacking AMPA receptors, NASPM (20 $\mu \mathrm{M}$, incubation time at least $30 \mathrm{~min})$ 
A

CONTROL

$-70 \mathrm{mV}$
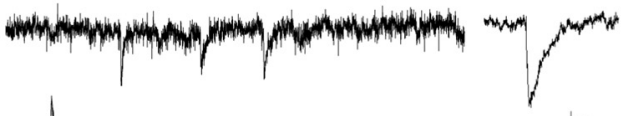

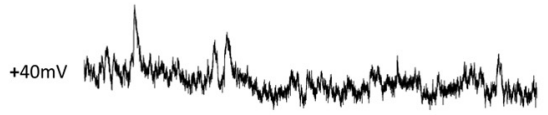

LIDOCAINE

$-70 \mathrm{mV}$

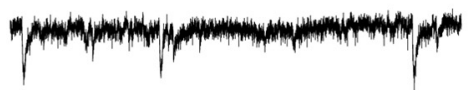

$+40 \mathrm{mV}$

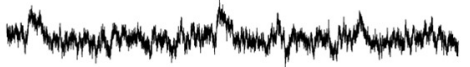

$10 \mathrm{pA} \quad 300 \mathrm{~ms}$
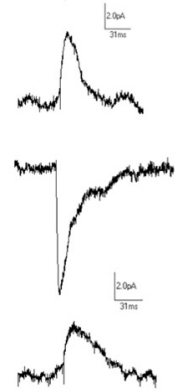

B

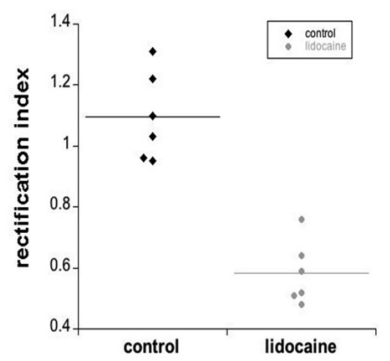

Figure 5. Inward rectification of AMPAergic mPSCs is increased in activity-blocked embryos. A, Pharmacologically isolated AMPAergic mPSCs at $-70 \mathrm{mV}$ (top) and $40 \mathrm{mV}$ (bottom) holding potentials are shown for control and activity-blocked motoneurons. Traces of $\mathrm{mEPSC}$ on the right are averages of all $\mathrm{mEPSC}$ for a single cell in each condition (control or lidocaine at $40 \mathrm{mV}$ and $-70 \mathrm{mV} ; n=6$ for control or treated). These records are made with spermine included in the patch solution. $\boldsymbol{B}$, Scatter plots show values of rectification index (amplitude at $40 \mathrm{mV} /$ amplitude at $-70 \mathrm{mV}$ ) for AMPAergic mPSCs from control and activity-blocked motoneurons ( $n=6$ for control or treated). $p<0.01$. RMS values were $1.06 \pm 0.11$ and $1.36 \pm 0.21$ at $-70 \mathrm{mV}$ for control and lidocaine-treated motoneurons, respectively; and $1.64 \pm 0.33$ and $2.20 \pm 0.24$ at $40 \mathrm{mV}$ for control and lidocaine-treated motoneurons, respectively.

A

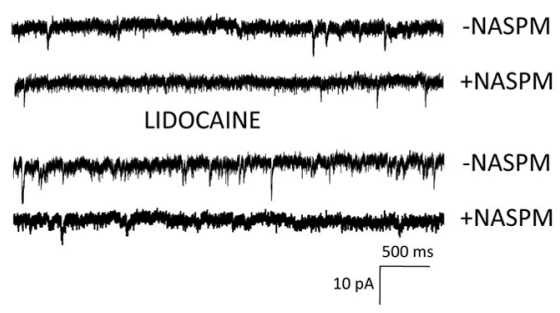

C

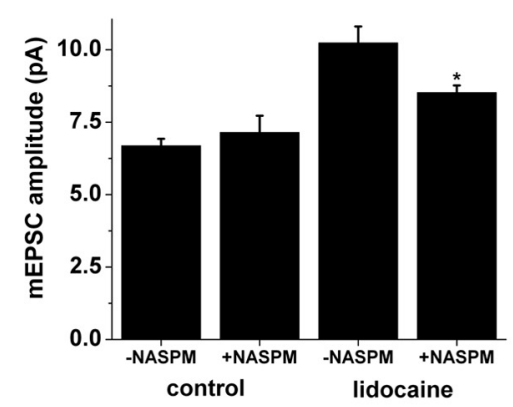

B
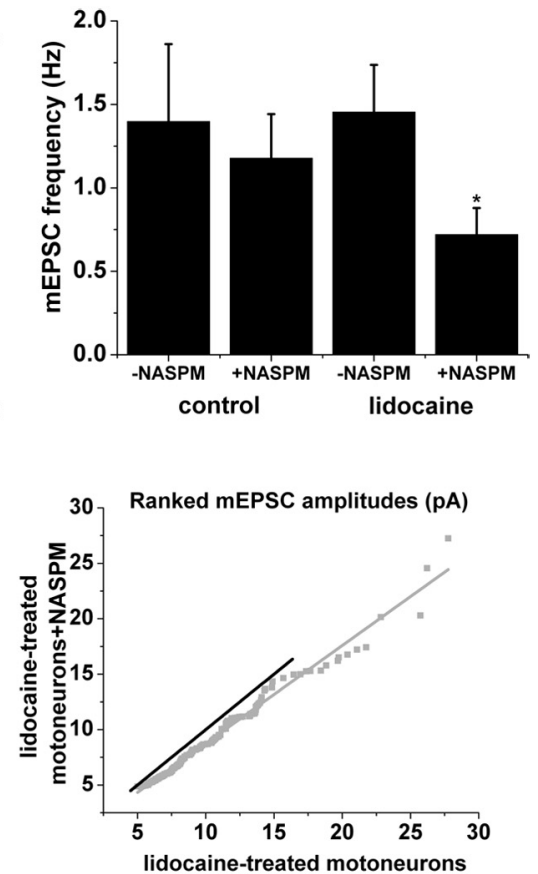

Figure 6. Activity-blocked motoneurons scale up mEPSCs through the insertion of GluA2-lacking AMPA receptors. $\boldsymbol{A}$, Whole-cell voltage-clamp recordings from motoneurons of control and lidocaine-treated embryos before and after the addition of NASPM. $\boldsymbol{B}$, Bar chart represents average values of mEPSC frequency before and after addition of NASPM in control $(n=7)$ and lidocainetreated $(n=8)$ motoneurons. ${ }^{*} p<0.001$. C, Bar chart represents average mEPSC amplitude before and after addition of NASPM in control $(n=7)$ and lidocaine-treated $(n=8)$ motoneurons. ${ }^{*} p<0.05$. $\boldsymbol{D}$, Ranked mEPSC amplitudes from activity-blocked motoneurons before ( $x$-axis) and after ( $y$-axis) adding NASPM $(n=6)$. The results show that amplitude values in NASPM are reduced in a multiplicative manner across their distribution. Black line represents expected result if amplitude distributions were the same. Error bars indicate SE. RMS values were $1.10 \pm 0.12$ and $1.23 \pm 0.10$ for control and lidocaine-treated motoneurons before the addition of NASPM, respectively; and $1.29 \pm 0.14$ and $1.00 \pm 0.11$ for control and lidocaine-treated motoneurons after the addition of NASPM, respectively.

(Hollmann et al., 1991; Koike et al., 1997). We show in Figure $6 A-C$ that, in activity-blocked motoneurons, bath application of NASPM dramatically reduced AMPAergic mEPSC frequency to $50 \%$ (from $1.45 \pm 0.28 \mathrm{~Hz}$ to $0.72 \pm 0.16 \mathrm{~Hz}, n=8 ; p<0.001$ ), and reduced $\mathrm{mEPSC}$ amplitude to $83 \%$ (from $10.2 \pm 0.6 \mathrm{pA}$ to $8.5 \pm 0.2 \mathrm{pA} ; p<0.05)$. We believe the reduction in $\mathrm{mEPSC}$ frequency is not a presynaptic effect of the drug but rather the result of the blockade of postsynaptic receptors, which is likely to reduce many mEPSCs below our ability to detect them (see Discussion). This finding, combined with the results from the rectification index, showed that mEPSCs from lidocainetreated motoneurons were mediated by both CP-AMPARs and CI-AMPARs. However, in control motoneurons, NASPM had no effect on AMPAergic mEPSC frequency (from $1.39 \pm 0.46 \mathrm{~Hz}$ to $1.18 \pm 0.27 \mathrm{~Hz}, n=$ 8) or amplitude (from $6.7 \pm 0.1 \mathrm{pA}$ to $7.1 \pm$ $0.6 \mathrm{pA}$; Fig. $6 \mathrm{C}$ ), suggesting that control mEPSCs are predominantly mediated by GluA2-containing CI-AMPARs. We compared the distribution of mEPSC amplitudes before and after adding NASPM in activity-blocked motoneurons (Fig. 6D). This allowed us to compare two somewhat different populations of mEPSCs: the total population of mEPSCs mediated by both CP-AMPARs and CI-AMPARs (before NASPM), and a subset of those mEPSCs (after NASPM) that were mediated by CIAMPARs. These two different populations might not be expected to be similar, but indeed their amplitude distributions were highly related through a multiplicative factor of $0.88(r=0.99$; slope $=0.88 \pm 0.01$; Fig. $6 D$ ). This slope is likely to be an overestimate of the true slope, as low amplitude mEPSCs likely fall into the noise after NASPM. Collectively, our biochemical and electrophysiological data suggest that the increase of AMPAergic mEPSC amplitude and conductance observed in motoneurons from activity-blocked embryos is mediated by increasing the population of GluA2lacking CP-AMPARs.

\section{GluA2-lacking AMPA receptors} mediate AMPAergic synaptic scaling after $\mathrm{GABA}_{\mathrm{A}}$ receptor blockade Previously, we have shown that AMPAergic synaptic scaling can be triggered in a very effective manner by blocking $\mathrm{GABA}_{\mathrm{A}}$ transmission in ovo (Wilhelm and Wenner, 2008). We repeated these experiments by injecting gabazine in ovo at $\mathrm{E} 8$ and recorded mEPSCs in motoneurons from E10 embryos. Plotting rank-ordered mEPSC amplitudes from control versus gabazinetreated motoneurons demonstrated an upward scaling of the mEPSCs $(r=0.98$; slope $=2.12 \pm 0.03$; Fig. $7 A$ ). Additionally, gabazine treatment induced a strong reduction in the total level of the GluA2 subunit in the ventral cord ( $36.9 \pm 1.8 \%$ of control value, $p<0.01$; Fig. $7 B$ ). To determine whether blocking activity or GABAergic transmission trigger scaling through the same mecha- 


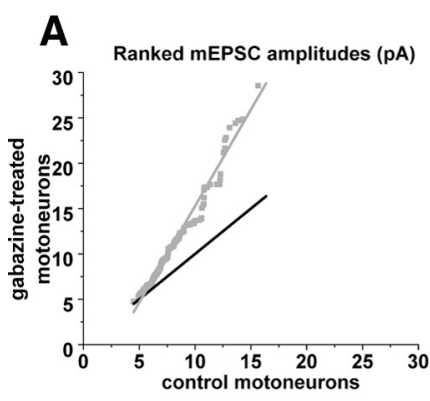

E

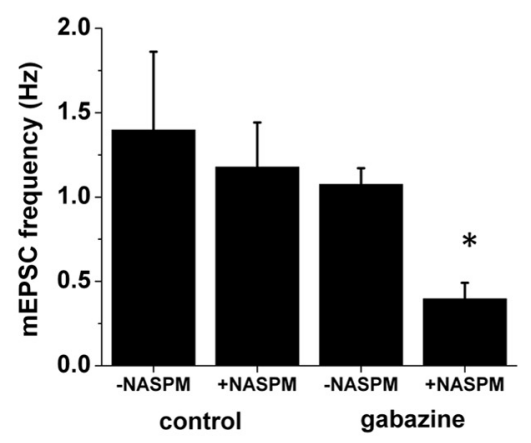

B C

GLUA2

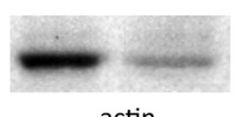

actin

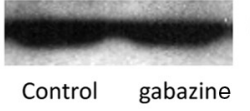

\section{.}

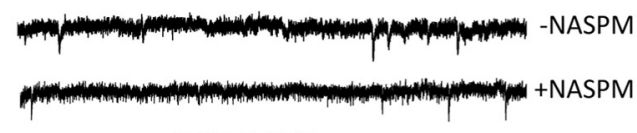

GABAZINE

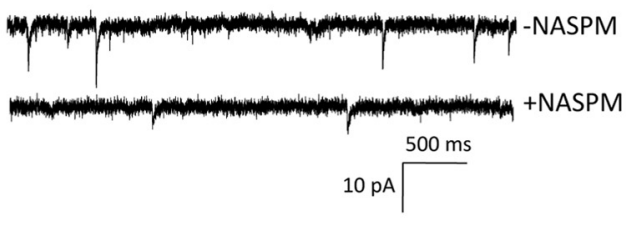

D

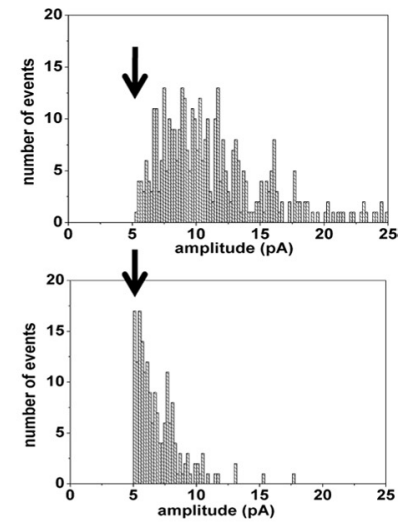

F

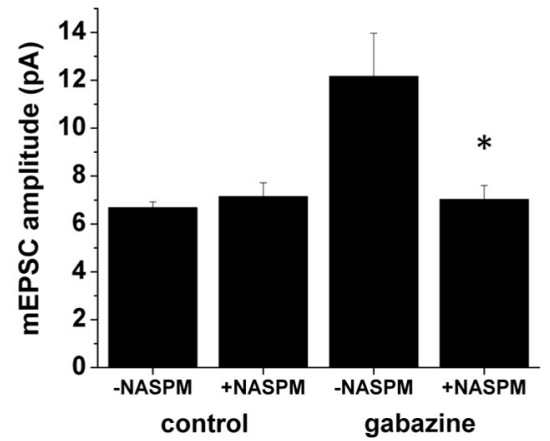

G

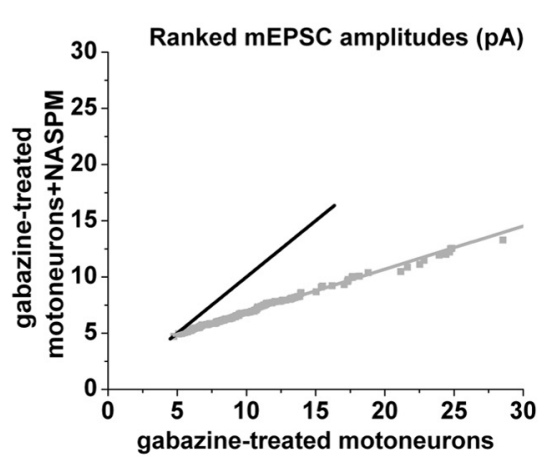

Figure 7. $G_{A B A_{A}}$ transmission blockade scales mEPSCs through insertion of GluA2-lacking AMPA receptors. $A$, Ranked mEPSC amplitudes from gabazine-treated motoneurons ( $y$-axis) plotted against corresponding ranked values of control motoneurons ( $x$-axis). Black line represents expected result if amplitude distributions were the same. $\boldsymbol{B}$, Western blots are shown for GluA2 (upper bands) and actin (lower bands) of ventral-half spinal cords from control and gabazine-treated embryos. The average values of band intensity (normalized to actin) for the GluA2 subunit was significantly reduced ( $p<0.01$ ) between control and gabazine-treated embryos. C, Whole-cell voltage-clamp recording of motoneurons from control and gabazine-treated embryos before and after the addition of NASPM. D, Histograms of mEPSC amplitude in gabazine-treated motoneurons before (upper histogram, $n=392 \mathrm{mEPSCS}$ ) and after (lower histogram, $n=270 \mathrm{mEPSC}$ ) bath application of NASPM. E, Bar chart shows average values of mEPSC frequency before and after addition of NASPM in control $(n=7)$, and gabazine-treated $(n=8)$ motoneurons. ${ }^{*} p<0.001 . F$, Bar chart shows average values of mPSC amplitude before and after addition of NASPM in control $(n=7)$, and gabazine-treated $(n=8)$ motoneurons. ${ }^{*} p<0.001$. $\boldsymbol{C}, \boldsymbol{E}, \boldsymbol{F}$, Control traces and values are the same as in Figure 6. G, Ranked mEPSC amplitudes from gabazine-treated motoneurons before $(x$-axis) and after ( $y$-axis) adding NASPM $(n=8)$. The results show that amplitude values in NASPM are reduced in a multiplicative manner across their distribution. Black line represents expected result if amplitude distributions were the same. Error bars indicate SE. RMS values were $1.10 \pm 0.12$ and $1.06 \pm 0.10$ for control and gabazine-treated motoneurons before the addition of NASPM, respectively; and $1.29 \pm 0.14$ and $1.04 \pm 0.07$ for control and gabazine-treated motoneurons after the addition of NASPM, respectively.

nisms, we tested the effect of NASPM on AMPAergic mEPSC frequency from embryos where GABAergic transmission had been blocked from E8 to E10. We show the effects of NASPM on gabazine-treated motoneurons (Figure $7 C-G$ ). The entire distribution of mEPSC amplitudes was reduced after NASPM application, such that a significant population of mEPSCs was reduced below our detection cutoff (5 pA, Fig. $7 D$, arrow). NASPM dramatically reduced AMPAergic mEPSC frequency to $37 \%$ (from $1.07 \pm 0.10 \mathrm{~Hz}$ to $0.40 \pm 0.09 \mathrm{~Hz}, n=8 ; p<0.001 ;$ Fig. $7 E$ ), and reduced mEPSC amplitude to $57 \%$ (from $12.2 \pm 1.8 \mathrm{pA}$ to $7.0 \pm 0.6 \mathrm{pA} ; p<0.001$; Fig. $7 F$ ). We compared the ranked distribution of mEPSC amplitudes before and after adding NASPM in $\mathrm{GABA}_{\mathrm{A}}$-blocked motoneurons and found that the amplitude distributions were highly related through a multiplicative factor of $0.38(r=0.99$; slope $=$ $0.38 \pm 0.01$; Fig. $7 G$ ). The changes produced by gabazine treatment were greater than for activity blockade. Together, these results suggest the appearance of synaptic GluA2-lacking AMPA receptors as a common molecular mechanism for AMPAergic scaling after the blockade of $\mathrm{SNA}$ or $\mathrm{GABA}_{\mathrm{A}}$ receptors in ovo.

AMPAergic scaling does not appear to be the result of a delayed development of AMPAergic currents

We considered the possibility that the drug treatments could induce a delay in the normal developmental transition in the chick embryo spinal cord from GluA2-lacking receptors at E6 to
GluA2-containing receptors by E11 that has been described previously (Ni et al., 2007). First, we assessed GluA2 protein levels in the control ventral spinal cord at E8 (onset of drug treatments) and E10 (end of treatment) using Western blot analysis. We found no difference in GluA2 levels at the 2 stages (Fig. 8), consistent with the idea that the developmental transition to GluA2containing receptors had largely occurred by E8. This result stands in contrast to the reduction of GluA2 protein observed after lidocaine treatment (Fig. 4) or gabazine treatment (Fig. 7B), suggesting that the treatment-induced changes in GluA2 protein levels do not reflect a developmental process in any simple way. Further, if the drug treatments caused a developmental delay in the maturation of the mEPSCs, then we might expect that mEPSC amplitude after the treatments at E10 would be of similar size to mEPSC amplitude at E8. Whole-cell recordings demonstrated that mEPSC amplitude at E8 was smaller than E10-treated motoneurons but was no different from E10 control motoneurons (E8 mEPSC amplitude, $8.1 \pm 0.9 \mathrm{pA}, n=6$; no different from E10 control, $p=0.79$, significantly reduced compared with lidocainetreated, $p=0.04$, and gabazine-treated, $p=0.02$, values shown above). Although the results do not absolutely rule out a developmental delay of some aspect of AMPAergic maturation, they are more consistent with a model where activity/transmission blockade triggers the replacement of existing CI-AMPARs by CPAMPARs (see Discussion). 


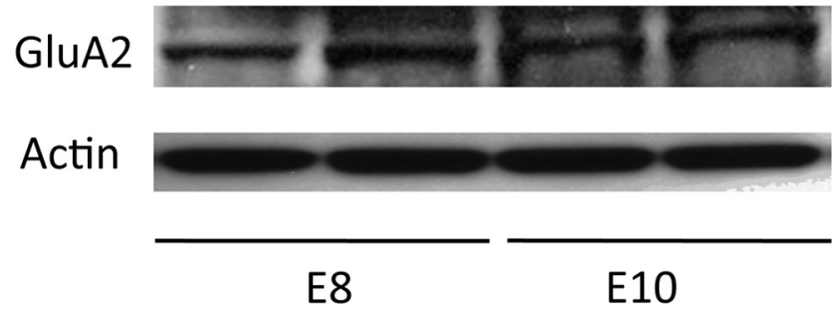

Figure 8. GluA2 protein levels in the control ventral spinal cord are the same at E8 and E10. Western blots are shown for GluA2 (upper bands) and actin (lower bands). The average values of band intensity (normalized to actin) for the GluA2 subunit were not significantly different between E8 $(0.34 \pm 0.02)$ and E10 $(0.33 \pm 0.01)$.

\section{Discussion}

Evidence for AMPAergic synaptic scaling is extensive and has been described by many different laboratories in several different systems in vitro and in vivo (Pozo and Goda, 2010; Turrigiano, 2012; Vitureira et al., 2012). No such consensus exists for the mechanisms underlying AMPAergic synaptic scaling, as several studies either support or deny the contribution of CP-AMPARs. Most work has assessed scaling mechanisms after in vitro perturbations; we show that AMPAergic scaling, in embryonic motoneurons after in vivo blockade of either spiking activity or GABAergic transmission, occurs through an increased mEPSC conductance mediated by the postsynaptic insertion GluA2lacking CP-AMPARs, at the expense of CI-AMPARs.

\section{AMPAergic synaptic scaling is dependent on CP-AMPARs in embryonic motoneurons in vivo}

Many studies have shown that AMPAergic scaling is mediated by changes in AMPA receptors in the postsynaptic membrane. Consistent with changes in postsynaptic receptors, we show that scaling is mediated by increases in mEPSC conductance. More importantly, we find that the increased mEPSC conductance was mediated by the insertion of CP-AMPARs. These GluA2-lacking AMPA receptors are distinct from GluA2-containing AMPA receptors in that they are permeable to $\mathrm{Ca}^{2+}$, have larger singlechannel conductance, and exhibit a voltage-dependent block by intracellular polyamines (Hollmann et al., 1991; Bowie and Mayer, 1995; Donevan and Rogawski, 1995; Swanson et al., 1997; Traynelis et al., 2010). We demonstrate the insertion of CPAMPARs after activity blockade in several ways: (1) through a reduction in GluA2 subunit expression in the ventral cord, (2) by the appearance of AMPAergic mPSCs that are sensitive to NASPM, and (3) by showing that mEPSCs in lidocaine-treated motoneurons express stronger inward rectification. Although we did not directly show increased calcium permeability of GluA2lacking receptors, several other studies have shown that the glutamate receptors that express an inward rectification and are sensitive to polyamines (e.g., NASPM) are permeable to calcium (Hollmann et al., 1991; Bowie and Mayer, 1995; Donevan and Rogawski, 1995); one study in particular demonstrated that rectification was a good indicator of calcium-permeable glutamate receptors in motoneurons in the chick embryo (Ni et al., 2007).

It is important to understand whether CP-AMPARs are involved in synaptic scaling because these receptors can influence calcium signaling pathways. As a result, many studies have assessed the contribution of the GluA2 subunit to synaptic scaling in cultured networks. Several of these in vitro studies have demonstrated an accumulation of GluA2-lacking CP-AMPARs (Ju et al., 2004; Thiagarajan et al., 2005; Sutton et al., 2006; Aoto et al., 2008; Hou et al., 2008; Beique et al., 2011). Other studies report

GluA2-containing AMPA receptor 1 GluA2-lacking AMPA receptor $\bigcirc$ below detection

\section{control -HH HHH - HHHHH-}
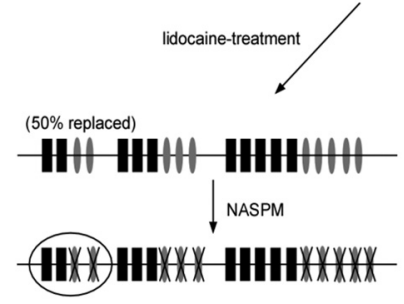

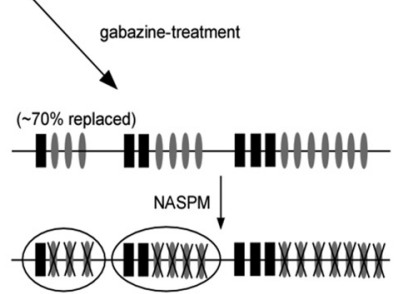

Figure 9. Model for synaptic scaling mediated by the insertion of GluA2-lacking AMPA receptors. Model shows GluA2-lacking AMPA receptors replacing existing GluA2-containing receptors in a 1:1 manner. Gabazine treatment produces a larger increase in mEPSC amplitude than activity blockade. This is consistent with a model where a greater proportion of GluA2containing receptors are replaced with the NASPM-sensitive GluA2-lacking receptors. Such a model would explain why NASPM reduces the frequency of mEPSCs in gabazine-treated motoneurons to a greater extent than for activity-blocked motoneurons, as more of the mEPSC $s$ fall below detection.

an upregulation of GluA2-containing CI-AMPARs after activity blockade (O'Brien et al., 1998; Sun et al., 2005; Wierenga et al., 2005; Sutton et al., 2006; Cingolani et al., 2008; Ibata et al., 2008; Anggono et al., 2011). Different results could arise from the method of blocking activity, the duration of the blockade, the tissue, or stage of development (Man, 2011; Lee, 2012; Shepherd, 2012). To look at the contribution of CP-AMPARs in a more natural context, two different groups have assessed the mechanisms of AMPAergic scaling after reductions in activity in vivo. Layer $2 / 3$ pyramidal cells in the primary visual cortex exhibit AMPAergic scaling after $2 \mathrm{~d}$ of reduced visual drive in the 3-week-old rat in vivo (Goel et al., 2006, 2011; Gainey et al., 2009). Surprisingly, one group found that scaling was mediated by CP-AMPARs (Goel et al., 2006, 2011), whereas the other group found that scaling involved CI-AMPARs (Gainey et al., 2009). Here, we test the role of CP-AMPARs in AMPAergic scaling after in vivo perturbations to a different network, at a stage when GABA is excitatory. In embryonic motoneurons, we find that CP-AMPARs mediate AMPAergic scaling at the expense of CI-AMPARs.

\section{Model for AMPAergic scaling in embryonic motoneurons}

We propose a model that we believe is the most consistent and parsimonious explanation for our findings: (1) after activity- or GABAergic-blockade scaling of mEPSCs is mediated by the replacement of GluA2-containing receptors by GluA2-lacking receptors; and (2) GABAergic blockade triggers scaling more effectively than lidocaine treatment by replacing a greater proportion of the CI-AMPARs with the higher conductance CPAMPARs (Fig. 9). Several findings contribute to this model. In support of the idea that CP-AMPARs are inserted at the expense of GluA2-containing receptors, we found that the GluA2 protein is reduced after scaling. Further, although mEPSC frequency was the same for control and treated (lidocaine or gabazine) motoneurons, blockade of CP-AMPARs with NASPM acutely reduced mEPSC frequency only for the treated cells (to $50 \%$ for lidocaine treatment, to $37 \%$ for gabazine treatment). Gabazine treatment may have produced a stronger increase in mEPSC amplitude than lidocaine treatment because more CI-AMPARs were replaced with CP-AMPARs (Fig. 9); when CP-AMPARs were then acutely blocked with NASPM, fewer CI-AMPARs remained 
to contribute to mEPSCs; therefore, many mEPSCs fell below detection (Fig. 7D) and dramatically reduced mEPSC frequency.

The idea that synaptic scaling is mediated by the insertion of CP-AMPARs at the expense of existing CI-AMPARs is distinct from many previous reports. Studies that have implicated GluA2lacking CP-AMPARs suggest that scaling is mediated by the addition of CP-AMPARs to the existing population of CI-AMPARs (Ju et al., 2004; Thiagarajan et al., 2005; Sutton et al., 2006; Hou et al., 2008; Jakawich et al., 2010). In our model, because CPAMPARs conduct more current than the CI-AMPARs, synaptic sites could have the same number of receptors but produce larger mEPSCs because of an increased proportion of CP-AMPARs. Two previous reports examining AMPAergic homeostatic plasticity in cortical neurons have shown evidence in favor of an insertion of CP-AMPARs at the expense of CI-AMPARs (Beique et al., 2011; He et al., 2012).

We favor the idea that CP-AMPARs replaced CI-AMPARs proportionally (i.e., as a percentage, dependent on the size of the existing population of CI-AMPARs). We found that, after 2-day treatments, mEPSC amplitudes scaled upward by a multiplicative factor (1.68, idocaine; 2.12, gabazine). This suggested all of the synapses mediating mEPSCs got stronger following in ovo treatment relative to their starting values (Turrigiano et al., 1998). Similarly, in treated motoneurons (lidocaine or gabazine), the population of mEPSC amplitudes before and after application of NASPM were multiplicatively scaled, even though these represent different populations of mEPSCs (Figs. $6 D$ and $7 G$ ). Therefore, the total population of mEPSCs (CP-AMPARs + CI-AMPARs) was related to the CI-AMPAR-mediated mEPSCs by a multiplicative scaling factor. This suggested that the new CP-AMPARs were added relative to the existing CIAMPAR population.

The model will need to be further tested, and certain aspects of the model may need to be adjusted. We cannot rule out the possibility that NASPM reduces mEPSC frequency by blocking CPAMPARs presynaptically; however, we do not favor this idea for several reasons. (1) The change in rectification index after scaling demonstrates an increase in CP-AMPARs postsynaptically. (2) There is no reduction of mEPSC frequency in control E10 motoneurons after NASPM application. (3) Virtually all AMPAergic scaling studies that have looked have found changes in postsynaptic AMPA receptors. Further, the model may only represent one stage of the plasticity. Certain studies have suggested that, after activity blockade, and the transition from CI-AMPARs to CP-AMPARs, there is a second step in the process where the receptors transition back to their CI-AMPAR state (Sutton et al., 2006; Hou et al., 2008; Man, 2011). Future experiments will be necessary to determine whether our findings represent the first step in scaling, which may then be followed by a return to CIAMPARs. Such a multistep process could potentially explain why some studies observe scaling mediated by CP-AMPARs and others by CI-AMPARs, as a function of the stage to which the plasticity has progressed.

\section{Reductions in activity and GABAergic transmission trigger the same mechanism of AMPAergic synaptic scaling}

In both the current and previous studies, we have demonstrated that blocking spiking activity in ovo triggers an upward synaptic scaling of glutamatergic mEPSCs but that blocking GABA $_{\mathrm{A}}$ transmission in ovo triggers an even greater increase in AMPAergic scaling (Gonzalez-Islas and Wenner, 2006; Wilhelm and Wenner, 2008). On the other hand, blocking AMPAergic transmission in ovo did not trigger AMPAergic scaling (Wilhelm and
Wenner, 2008). Based on these previous findings, we postulated that activity block triggers scaling by reducing the release of $\mathrm{GABA}$, thereby reducing $\mathrm{GABA}_{\mathrm{A}}$ receptor activation. If GABAergic block and activity block really do trigger the same process, then the mechanisms underlying scaling should be the same. Here we show that both treatments involve the insertion of GluA2-lacking receptors. These findings strengthen the idea that the $\mathrm{GABA}_{\mathrm{A}}$ receptor is part of the sensing machinery that triggers compensatory changes in synaptic strength. We have observed that, compared with activity block, $\mathrm{GABA}_{\mathrm{A}}$ blockade is more effective at increasing mEPSC amplitude. This might result because gabazine blocks both evoked and spontaneous GABAergic currents, resulting in a more complete replacement of CI-AMPARs by CP-AMPARs. Future studies will be necessary to identify the steps that lie between reduced GABAergic currents and the scaling process; one such step could be increased cell excitability, which is known to occur within hours of reduced GABAergic transmission (Wilhelm et al., 2009).

\section{References}

Anggono V, Clem RL, Huganir RL (2011) PICK1 loss of function occludes homeostatic synaptic scaling. J Neurosci 31:2188-2196. CrossRef Medline

Aoto J, Nam CI, Poon MM, Ting P, Chen L (2008) Synaptic signaling by all-trans retinoic acid in homeostatic synaptic plasticity. Neuron 60:308 320. CrossRef Medline

Beique JC, Na Y, Kuhl D, Worley PF, Huganir RL (2011) Arc-dependent synapse-specific homeostatic plasticity. Proc Natl Acad Sci U S A 108: 816-821. CrossRef Medline

Blankenship AG, Feller MB (2010) Mechanisms underlying spontaneous patterned activity in developing neural circuits. Nat Rev Neurosci 11:18-29. CrossRef Medline

Bowie D, Mayer ML (1995) Inward rectification of both AMPA and kainate subtype glutamate receptors generated by polyamine-mediated ion channel block. Neuron 15:453-462. CrossRef Medline

Cingolani LA, Thalhammer A, Yu LM, Catalano M, Ramos T, Colicos MA, Goda Y (2008) Activity-dependent regulation of synaptic AMPA receptor composition and abundance by $\beta 3$ integrins. Neuron $58: 749-762$. CrossRef Medline

Donevan SD, Rogawski MA (1995) Intracellular polyamines mediate inward rectification of $\mathrm{Ca}(2+)$-permeable alpha-amino-3-hydroxy-5methyl-4-isoxazolepropionic acid receptors. Proc Natl Acad Sci U S A 92:9298-9302. CrossRef Medline

Gainey MA, Hurvitz-Wolff JR, Lambo ME, Turrigiano GG (2009) Synaptic scaling requires the GluR2 subunit of the AMPA receptor. J Neurosci 29:6479-6489. CrossRef Medline

Goel A, Jiang B, Xu LW, Song L, Kirkwood A, Lee HK (2006) Cross-modal regulation of synaptic AMPA receptors in primary sensory cortices by visual experience. Nat Neurosci 9:1001-1003. CrossRef Medline

Goel A, Xu LW, Snyder KP, Song L, Goenaga-Vazquez Y, Megill A, Takamiya K, Huganir RL, Lee HK (2011) Phosphorylation of AMPA receptors is required for sensory deprivation-induced homeostatic synaptic plasticity. PLoS One 6:e18264. CrossRef Medline

Gonzalez-Islas C, Wenner P (2006) Spontaneous network activity in the embryonic spinal cord regulates AMPAergic and GABAergic synaptic strength. Neuron 49:563-575. CrossRef Medline

Gonzalez-Islas C, Chub N, Wenner P (2009) NKCC1 and AE3 appear to accumulate chloride in embryonic motoneurons. J Neurophysiol 101: 507-518. CrossRef Medline

Gonzalez-Islas C, Chub N, Garcia-Bereguiain MA, Wenner P (2010) GABAergic synaptic scaling in embryonic motoneurons is mediated by a shift in the chloride reversal potential. J Neurosci 30:13016-13020. CrossRef Medline

Hamburger V, Hamilton HL (1951) A series of normal stages in the development of the normal chick embryo: 1951. Dev Dyn 195:231-272. CrossRef Medline

He K, Petrus E, Gammon N, Lee HK (2012) Distinct sensory requirements for unimodal and cross-modal homeostatic synaptic plasticity. J Neurosci 32:8469-8474. CrossRef Medline

Hollmann M, Hartley M, Heinemann S (1991) $\mathrm{Ca}^{2+}$ permeability of KA- 
AMPA-gated glutamate receptor channels depends on subunit composition. Science 252:851-853. CrossRef Medline

Hou Q, Zhang D, Jarzylo L, Huganir RL, Man HY (2008) Homeostatic regulation of AMPA receptor expression at single hippocampal synapses. Proc Natl Acad Sci U S A 105:775-780. CrossRef Medline

Ibata K, Sun Q, Turrigiano GG (2008) Rapid synaptic scaling induced by changes in postsynaptic firing. Neuron 57:819-826. CrossRef Medline

Jakawich SK, Nasser HB, Strong MJ, McCartney AJ, Perez AS, Rakesh N, Carruthers CJ, Sutton MA (2010) Local presynaptic activity gates homeostatic changes in presynaptic function driven by dendritic BDNF synthesis. Neuron 68:1143-1158. CrossRef Medline

Ju W, Morishita W, Tsui J, Gaietta G, Deerinck TJ, Adams SR, Garner CC, Tsien RY, Ellisman MH, Malenka RC (2004) Activity-dependent regulation of dendritic synthesis and trafficking of AMPA receptors. Nat Neurosci 7:244-253. CrossRef Medline

Koike M, Iino M, Ozawa S (1997) Blocking effect of 1-naphthyl acetyl spermine on $\mathrm{Ca}(2+)$-permeable AMPA receptors in cultured rat hippocampal neurons. Neurosci Res 29:27-36. CrossRef Medline

Lazzaro JT, Paternain AV, Lerma J, Chenard BL, Ewing FE, Huang J, Welch WM, Ganong AH, Menniti FS (2002) Functional characterization of CP-465,022, a selective, noncompetitive AMPA receptor antagonist. Neuropharmacology 42:143-153. CrossRef Medline

Lee HK (2012) Ca-permeable AMPA receptors in homeostatic synaptic plasticity. Front Mol Neurosci 5:17. Medline

Man HY (2011) GluA2-lacking, calcium-permeable AMPA receptors: inducers of plasticity? Curr Opin Neurobiol 21:291-298. CrossRef Medline

Ni X, Sullivan GJ, Martin-Caraballo M (2007) Developmental characteristics of AMPA receptors in chick lumbar motoneurons. Dev Neurobiol 67:1419-1432. CrossRef Medline

O’Brien RJ, Kamboj S, Ehlers MD, Rosen KR, Fischbach GD, Huganir RL (1998) Activity-dependent modulation of synaptic AMPA receptor accumulation. Neuron 21:1067-1078. CrossRef Medline

O’Donovan MJ (1999) The origin of spontaneous activity in developing networks of the vertebrate nervous system. Curr Opin Neurobiol 9:94104. CrossRef Medline

O’Donovan MJ, Chub N, Wenner P (1998) Mechanisms of spontaneous activity in developing spinal networks. J Neurobiol 37:131-145. CrossRef Medline

Pozo K, Goda Y (2010) Unraveling mechanisms of homeostatic synaptic plasticity. Neuron 66:337-351. CrossRef Medline
Rich MM, Wenner P (2007) Sensing and expressing homeostatic synaptic plasticity. Trends Neurosci 30:119-125. CrossRef Medline

Shepherd JD (2012) Memory, plasticity and sleep: a role for calcium permeable AMPA receptors? Front Mol Neurosci 5:49. CrossRef Medline

Sun X, Zhao Y, Wolf ME (2005) Dopamine receptor stimulation modulates AMPA receptor synaptic insertion in prefrontal cortex neurons. J Neurosci 25:7342-7351. CrossRef Medline

Sutton MA, Ito HT, Cressy P, Kempf C, Woo JC, Schuman EM (2006) Miniature neurotransmission stabilizes synaptic function via tonic suppression of local dendritic protein synthesis. Cell 125:785-799. CrossRef Medline

Swanson GT, Kamboj SK, Cull-Candy SG (1997) Single-channel properties of recombinant AMPA receptors depend on RNA editing, splice variation, and subunit composition. J Neurosci 17:58-69. Medline

Thiagarajan TC, Lindskog M, Tsien RW (2005) Adaptation to synaptic inactivity in hippocampal neurons. Neuron 47:725-737. CrossRef Medline

Traynelis SF, Wollmuth LP, McBain CJ, Menniti FS, Vance KM, Ogden KK, Hansen KB, Yuan H, Myers SJ, Dingledine R (2010) Glutamate receptor ion channels: structure, regulation, and function. Pharmacol Rev 62:405496. CrossRef Medline

Turrigiano G (2012) Homeostatic synaptic plasticity: local and global mechanisms for stabilizing neuronal function. Cold Spring Harbor Perspect Biol 4:a005736. CrossRef Medline

Turrigiano GG (2008) The self-tuning neuron: synaptic scaling of excitatory synapses. Cell 135:422-435. CrossRef Medline

Turrigiano GG, Leslie KR, Desai NS, Rutherford LC, Nelson SB (1998) Activity-dependent scaling of quantal amplitude in neocortical neurons. Nature 391:892-896. CrossRef Medline

Vitureira N, Letellier M, Goda Y (2012) Homeostatic synaptic plasticity: from single synapses to neural circuits. Curr Opin Neurobiol 22:516-521. CrossRef Medline

Wierenga CJ, Ibata K, Turrigiano GG (2005) Postsynaptic expression of homeostatic plasticity at neocortical synapses. J Neurosci 25:2895-2905. CrossRef Medline

Wilhelm JC, Wenner P (2008) GABAA transmission is a critical step in the process of triggering homeostatic increases in quantal amplitude. Proc Natl Acad Sci U S A 105:11412-11417. CrossRef Medline

Wilhelm JC, Rich MM, Wenner P (2009) Compensatory changes in cellular excitability, not synaptic scaling, contribute to homeostatic recovery of embryonic network activity. Proc Natl Acad Sci U S A 106:6760-6765. CrossRef Medline 